\title{
Environmental Assessment of Compaction and Transportation of Municipal Solid Waste in Patna, India
}

\author{
Yash Aryan ${ }^{1}$, Deval Singh ${ }^{1}$ and Anil Kumar Dikshit ${ }^{1, *}$ \\ 1 Environmental Science and Engineering Department, Indian Institute of Technology Bombay, Powai, Mum- \\ bai 400076, India; yasharyance@gmail.com; devalsingh463@gmail.com; dikshit@iitb.ac.in \\ * Correspondence: dikshit@iitb.ac.in
}

\begin{abstract}
Municipal solid waste management is a major concern for developing countries all over the world. The collection and transportation accounts for major portion of expenditure in developing country like India. The compaction of waste is being practiced in some major cities of India as they provide economical benefit but the environmental benefits of compaction are not very clear. The preset study evaluates the environmental impacts due to transportation of non-compacted and compacted waste from the transfer station to the landfill site using life cycle assessment approach. The study compared transportation of non-compacted waste with the waste compacted by the truck mounted refuse compactor and portable stationary compactor. The functional unit defined was the amount of waste generated per day in the study area taken as Patna city and GaBi 10.5 used for impact assessment. The study found that the transportation of waste compacted by truck mounted refuse compactor had the least environmental impacts on all impact categories. The study recommends the compaction of waste by the truck mounted refuse compactor and then proceed for transportation. Also, the compaction of waste is recommended as it improve the overall environment performance of municipal solid waste management.
\end{abstract}

Keywords: compaction; environmental impacts; life cycle assessment; municipal solid waste; transportation

\section{Introduction}

Rapid urbanization and population growth have led to increased solid waste production on global scale [1]. Solid waste management (SWM) is a major challenge for many urban local bodies (ULB's) in India as well as other developing countries. Municipal solid waste (MSW) generation rate in India varies from $0.17 \mathrm{~kg}$ per person per day in small towns to $0.65 \mathrm{~kg}$ per person per day in major cities [2]. The production of solid waste in the world is expected to be approximately 27 billion tonnes per year by 2050, one-third of which will come from Asia, with major contributions from China and India [2]. In India, MSW generated as of January 2020 is 147,613 metric tonnes (MT) per day and is expected to increase to 1,195,000 MT per day by 2050 [3]. Collection and transportation (C\&T) of MSW is an essential and important part of SWM. C\&T of MSW is a major contributor to the overall cost, social indignation, air emissions, and fuel consumption in the entire management system [4]. In developing countries like India, C\&T accounts for major portion of the expenditure around 70-85\% while in developed countries like Sweden, UK, USA, C\&T accounts for $50-75 \%$ of the expenditure in total SWM cost [4].

Life cycle assessment (LCA) is a tool for evaluating the environmental impacts of any process, system or activity [1]. LCA approach is being widely used all over the world to compare the environmental impacts from various MSW management options [5]. Koushki et al. (2004) conducted study to determine C\&T cost of household SW in Kuwait [6]. The study found that mean haul distance ranged from $4.5 \mathrm{~km}$ to $32 \mathrm{~km}$. The study concluded that the collection, transportation and disposal cost was KD 7.5 (\$24.0) per ton of waste [6]. Alam et al. (2008) conducted study related to generation, collection, storage and 
transportation of MSW in Kathmandu, Nepal [7]. The study mentioned about the use of compactors in transfer station in year 2008, however there is no information about the efficiency of these compactors. The study found that $70-90 \%$ of generated waste was getting collected [7]. Yay (2015) performed LCA for identifying the best MSW management options in Sakarya, Turkey [8]. The functional unit adopted was 1 tonne of MSW generated and system boundary included collection, transportation and waste management alternatives. The study used SimaPro 8.0.2 software and CML-IA methodology to evaluate environmental impacts. The study assumed $19 \mathrm{~km}$ transportation distance between waste collection point and landfill site. The study considered unit process (lorry 21t) of transportation from Ecoinvent database of SimaPro. This study like most of the LCA study in MSW management focused mainly on management options and not on collection and transportation phase. The study mentioned that emissions of sulphur dioxide and nitrogen oxides during transportation contributed to the environmental impacts [8]. Baidya et al. (2016) conducted study for existing MSW management scenario in Kolkata, India [9]. The study focused on the use of compactors at the transfer station and analyzed the usefulness of the compactors in waste management system. The study did not evaluate any impacts of the compactors on the environment or its advantage in transportation of solid waste after collection [9]. Gilardino et al. (2017) identified the best collection router through optimization techniques in Lima, Peru [10]. The study also implemented LCA technique to evaluate the environmental impacts of existing and proposed collection systems. The functional unit defined was collection of 1 tonne of waste. The study analyzed the collection system containing compaction vehicles but did not evaluate the advantage or disadvantage towards environmental impacts due to compaction of waste. The study concluded that proposed container collection system had less environmental impacts compared to existing door to door collection system on most of the impact categories [10]. Rajcoomar \& Ramjeawon (2017) carried LCA study to evaluate the environmental impacts of MSW management options in Mauritius [11]. The MSW generated in 2010 was taken as functional unit and SimaPro software was used to perform impact assessment. The study considered midpoint and end-point approach-based impact assessment methodology. The system boundary included collection, transportation and waste management alternatives. The study found that the collection and transportation of waste had significant impacts on the environment under the end-point method approach [11]. Sharma \& Chandel (2017) assessed the environmental impacts of different waste management strategies in Mumbai, India [12]. The study considered six different strategies and the collection and transportation of MSW. The study concluded that there was no single MSW management scenario that had the lowest environmental impacts on all the impact categories [12]. Coelho \& Lange (2018) performed LCA to investigate the best MSW management scenario in Rio de Janeiro, Brazil [13]. The annual amount of waste generated was adopted as the functional unit and the study investigated various waste management scenarios. The system boundary considered the collection, transportation and management of MSW. The study considered transport of segregate waste as well as mixed waste. The study observed that diesel consumption was mainly related to waste collection and transport [13]. Yadav \& Samadder (2017) assessed the environmental impacts from different MSW management options in Dhanbad city, India [14]. The study adopted 1 tonne of MSW as the functional unit and SimaPro 8.0.1 software used for evaluating the impacts. The system boundary covered the collection, transportation and various waste management options. The study adopted CML 2 baseline 2000 method for impact assessment. The study considered collection and transportation of MSW under different individual scenarios. The scenario including collection and transportation had the highest impact on abiotic depletion (AD) impact category and marine aquatic ecotoxicity (MAE) impact category. The study did not consider any compaction of MSW [14]. Taskin \& Demir (2020) evaluated environmental and energy impacts of urban MSW collection and transportation using LCA approach in Turkey [1]. The functional unit defined was 1 ton of collected and transported MSW per day and SimaPro PhD 8.4.1.0 software was used for impact assessment. The CML-IA baseline method was adopted for evaluating the environmental impacts. The study found that the 
construction of transfer stations instead of landfills reduced the environmental impacts for all impact categories and cumulative energy demand rates [1]. Similarly, few other existing LCA studies evaluated the environmental impacts of various waste management options in India and considered a fixed distance between collection and landfill site to assess the impacts due to collection and transportation [15,16].

The existing LCA studies on MSW management mainly focused on the waste management options and not particularly on collection and transportation of MSW including benefits of compaction of MSW during collection and transportation. The compactor truck and portable stationary compactors (PSC) are being used at transfer stations in major cities of India for compacting the MSW. The compaction of MSW provides economic benefits in collection and transportation of MSW and compaction of MSW may also provide the environmental benefits during collection and transportation of MSW. The present study at evaluating the environmental benefits associated with compaction of MSW in compaction trucks and PSC.

\section{Methodology}

\subsection{Study Area}

The study area for the present study is Patna, the state capital of Bihar. Patna is one of the oldest cities located in the eastern part of India between Delhi and Kolkata. The population of Patna was around 1.683 million in 2011, which is $22.2 \%$ increase compared to population in 2001 [17]. The present estimated population is around 2.1 million considering the increase rate of $25 \%$ compared to population in 2011. The MSW management in Patna is looked upon by Patna Municipal Corporation (PMC). The PMC is divided into 75 wards, which are managed through 6 circles. The MSW generation in 2021 is around 1,514 tonnes per day (TPD) [17].

There are a total 25 compactors in all the 6 circles and the transfer station considered in this study is located in Gardanibagh area of Patna town. The location of transfer station is shown in Figure 1. The truck mounted refuse compactor (TMRC) and PSC are shown in Figure 2. The TMRC and PSC both are of $14 \mathrm{~m}^{3}$ and 16 tonnes capacity. The landfill site is in Ramchak Bairiya, which is approximately $10 \mathrm{~km}$ from the transfer station.

\subsection{Goal and Scope Definition}

The present study aims to evaluate the environmental impacts due to transportation of non-compacted and compacted MSW from transfer station to landfill site using LCA approach. The life cycle inventory (LCI) will be developed related to TMRC and PSC. The Centre for Environmental Studies (CML) 2001 and Tool for Reduction and Assessment of Chemicals and Other Environmental Impacts (TRACI) 2.1 method was adopted for impact assessment. The functional unit adopted is MSW generated per day in Patna (1,514 TPD). The system boundary includes the diesel and electricity consumption for compaction and transportation of the waste from the transfer station to the landfill site. The system boundary is shown in Figure 3. 


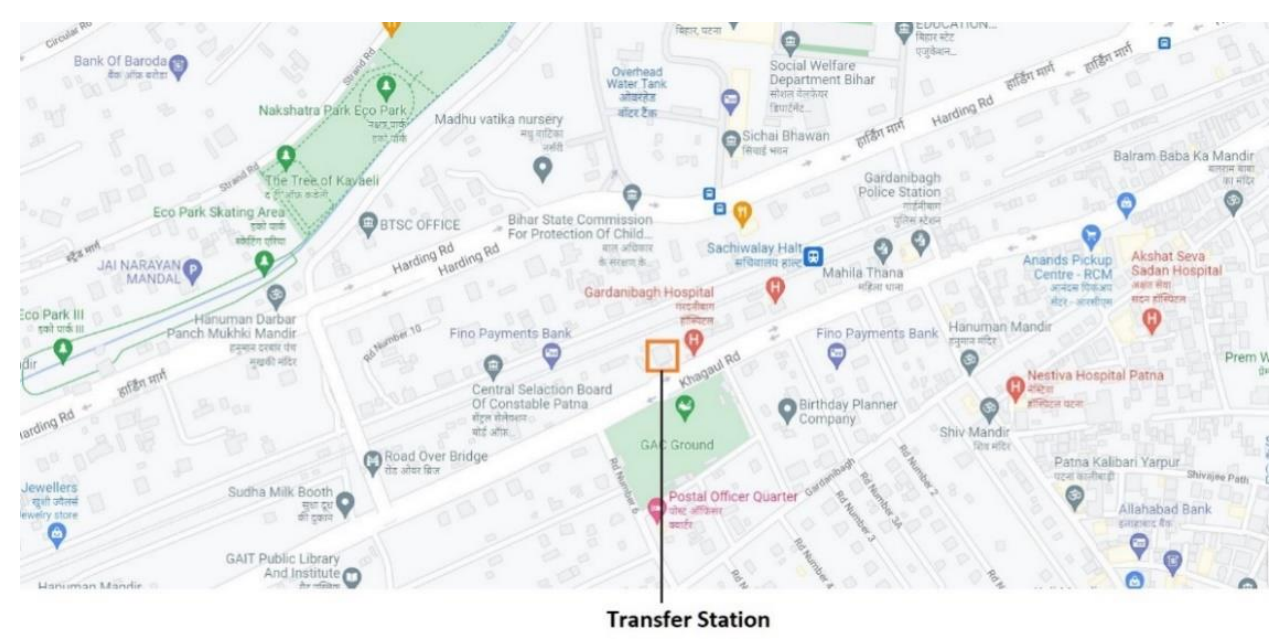

Figure 1. Location of transfer station

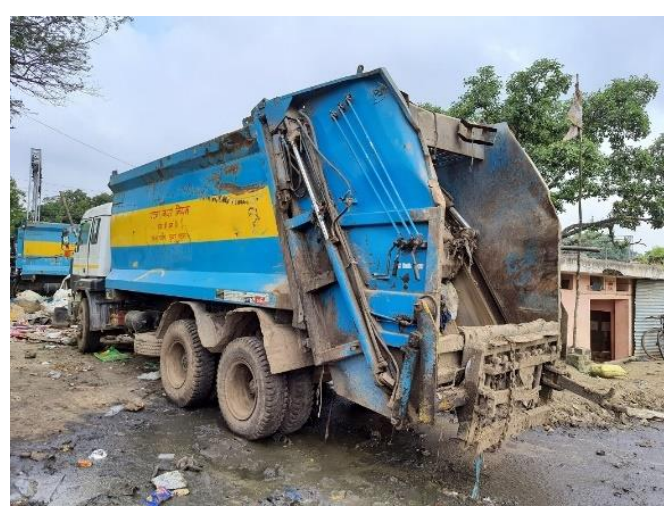

(a)

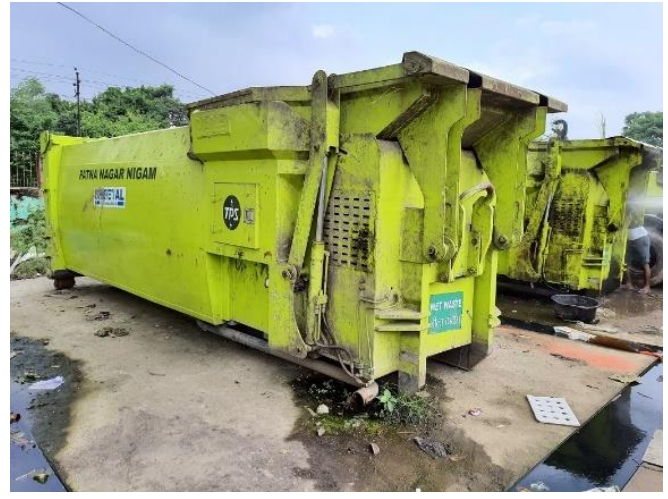

(b)

Figure 2. (a) Truck mounted refuse compactor (TMRC); (b) portable stationary compactor (PSC)

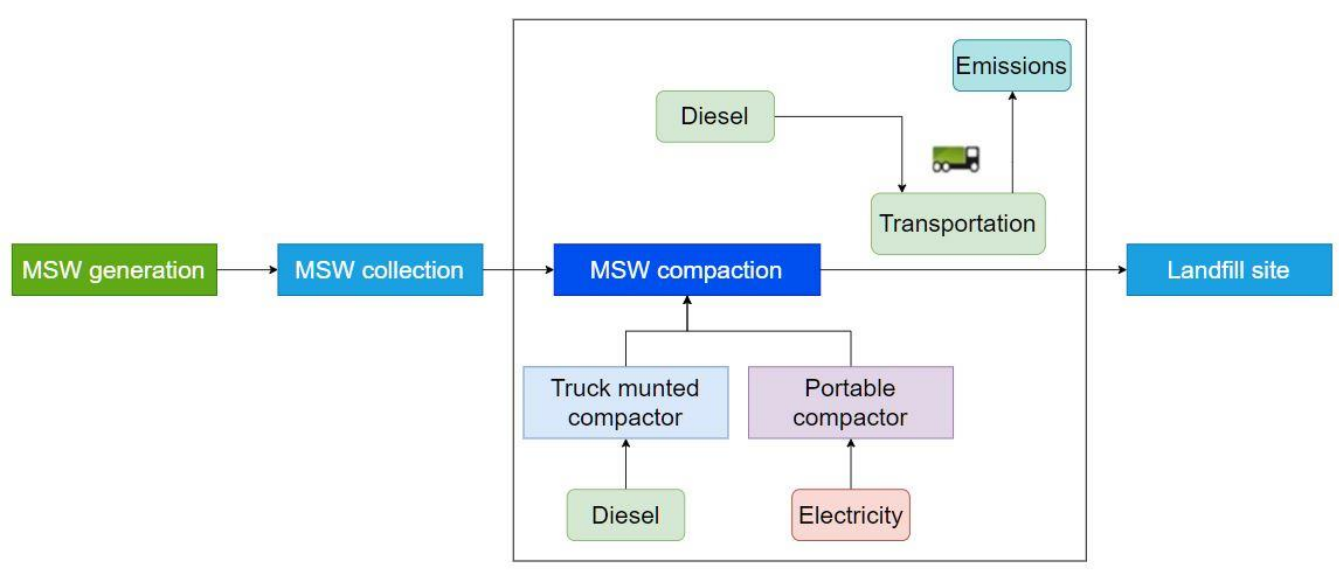

Figure 3. System boundary of the present study 


\subsection{Life Cycle Inventory}

LCI includes primary and secondary data. In the present study, primary data was collected via the interviews of the PMC workers at the transfer station and collection and transportation vehicle operators. The secondary data was collected from the literature review and GaBi database. TMRC takes 1.5 hours to load and compact the waste and consumes 3 litres diesel per hour during loading and compaction. PSC takes 2 hours to compact the waste and consumes $13.7 \mathrm{kw}$ electricity. The mileage of compactor vehicle is $2 \mathrm{~km}$ per liter and for the purposes of comparison, it has been assumed that non-compacted waste is also transported in the truck having same volume and capacity and similar mileage. According to the data obtained from the interview surveys, it was calculated that to transport non-compacted waste per functional unit, 239 trips per day shall be required while when waste was compacted, the number of trips required reduced to 103 per day.

\subsection{Life Cycle Impact Assessment}

Life cycle impact assessment (LCIA) phase quantifies the potential environmental impacts based on LCI data [18]. In this phase, the environmental loads are translated into environmental impacts using GaBi 10.5 software. A total of 6 impact categories were considered for consistent and meaningful understanding of environmental impacts - four impact categories [Abiotic Depletion (ADP fossil), Acidification Potential (AP), Global Warming Potential (GWP) and Human Toxicity Potential (HTP)] from CML 2001 method and two impact categories [Human Health Particulate Air (HHPA) and Smog Air (SA)] from TRACI 2.1 method. CML 2001 and TRACI 2.1 both are mid-point approach method and the impact categories present in both these methods are the most relevant for the present study.

\section{Results}

The environmental impacts due to transportation of non-compacted and compacted waste have been shown in Figures 4-9. As per the study, the waste that was not compacted and transported from the transfer station to landfill site had higher impacts on ADP fossil and GWP impact categories. While waste compacted in PCS and then transported had higher impacts on AP, HTP, HHPA and SA impact categories. The waste compacted in TMRC and then transported had the least environmental impact on all the impact categories. The transportation of non-compacted waste had highest impact on ADP fossil (50,500 MJ) impact category and GWP (3,760 kg CO 2 eq.) (Figures 4-5) due to much more consumption of diesel in transportation as the number of trips to transport non-compacted waste per functional unit was more.

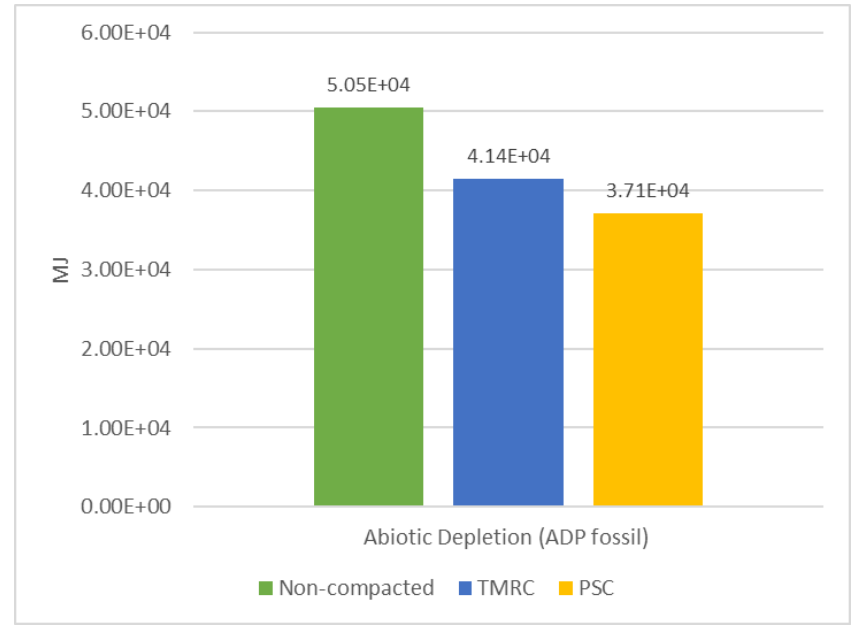

Figure 4. Environmental impacts on ADP fossil impact category 


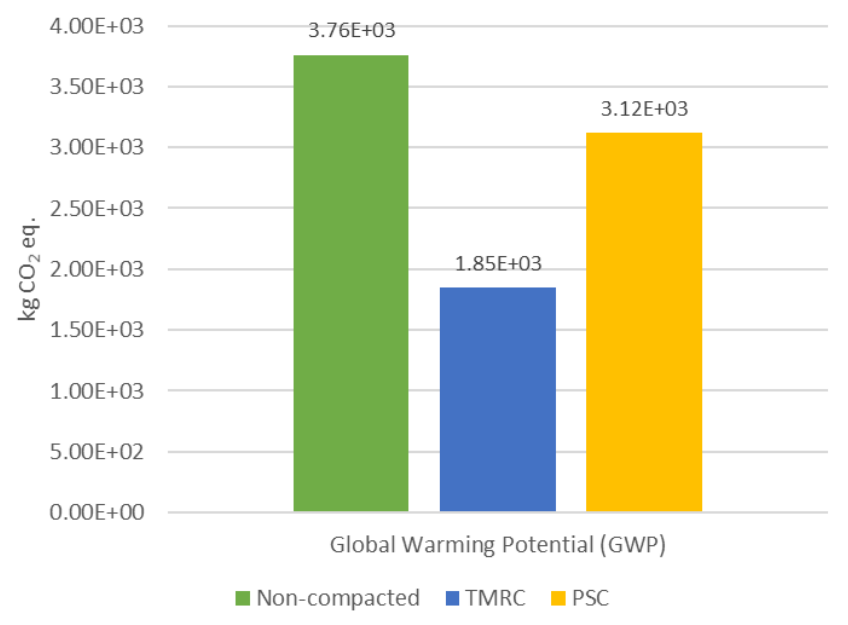

Figure 5. Environmental impacts on GWP impact category

The waste compacted by PSC and then transported to landfill site had highest environmental impacts on $19.6 \mathrm{~kg} \mathrm{SO} 2$ eq. AP impact category, $492 \mathrm{~kg}$ DCB eq. HTP impact category, $2.21 \mathrm{~kg}$ PM2.5 eq. HHPA impact category and $182 \mathrm{~kg} \mathrm{O}$ eq. SA impact category (Fig. 6-9). The PSC performed worse in four impact categories due to the consumption of high amount of electricity during compaction. This is due to the higher impacts associated with the electricity being generated in thermal power plant using coal in India.

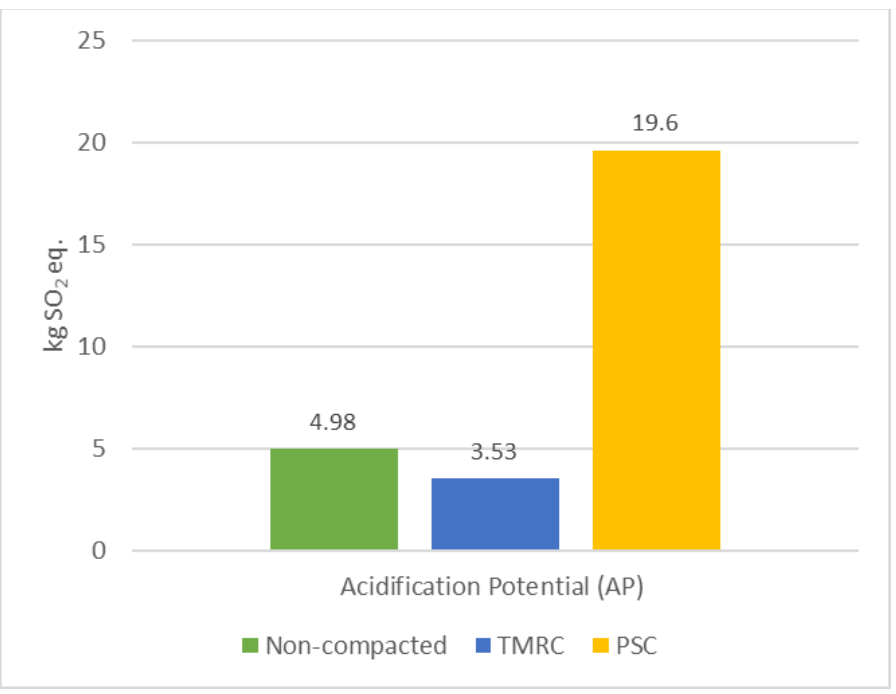

Figure 6. Environmental impacts on AP impact category 


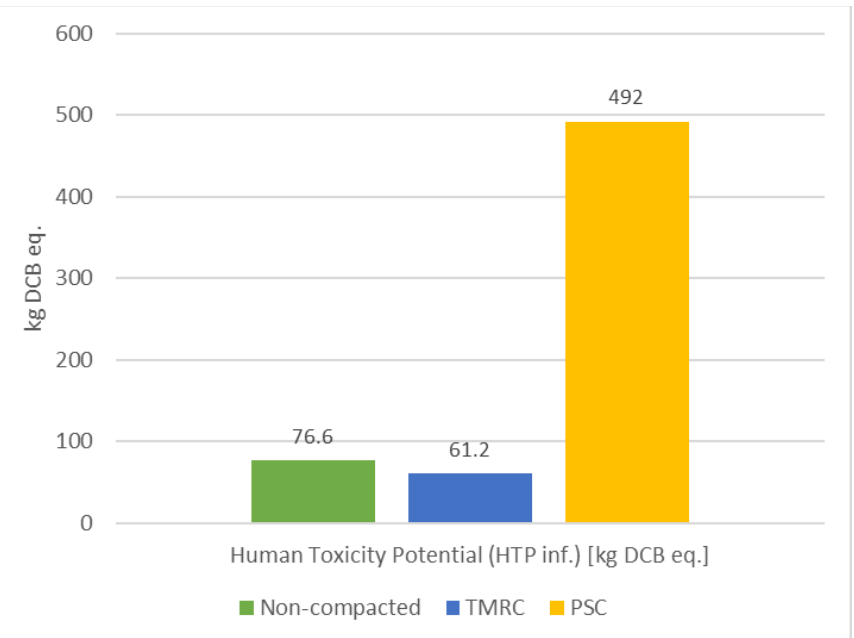

Figure 7. Environmental impacts on HTP impact category

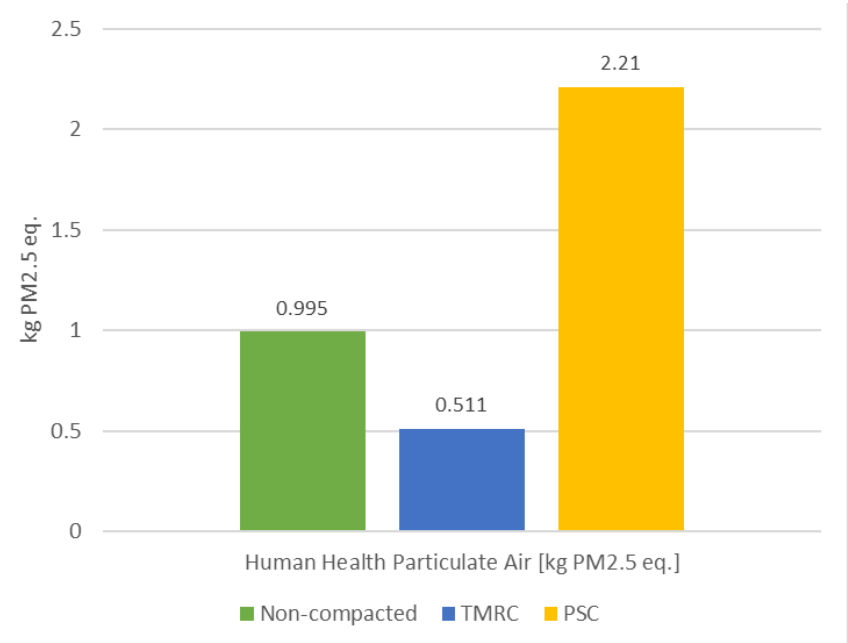

Figure 8. Environmental impacts on HHPA impact category

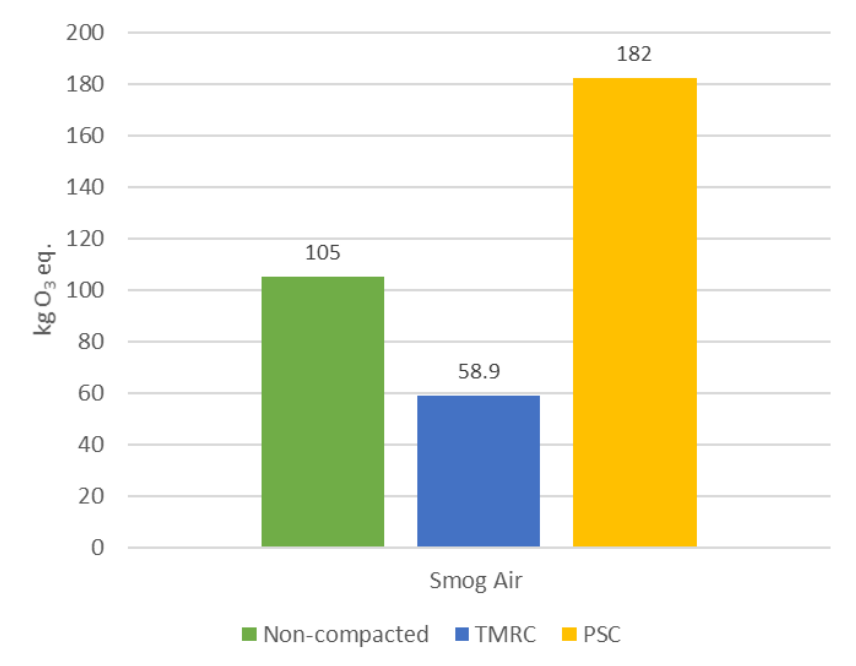

Figure 9. Environmental impacts on SA impact category 


\section{Conclusions}

It can be concluded that the waste compacted by TMRC had better environmental performance on all the impact categories while PSC performed the worst having highest impact categories on the four impact categories. The study suggests that all municipal corporation of cities in India should adopt waste compaction preferably using TMRC as it provides economic as well as environmental benefits. The non-compaction of waste should be avoided as the major and significant environmental impacts were observed on ADP fossil fuel and GWP impact category. PSC had highest impacts on remaining four impact categories but the impacts were not significant. The environmental performance of PSC can be enhanced by using alternative renewable source of electricity such as solar or wing. The compaction of MSW for sure results in overall better environmental performance of MSW management.

Funding: The funding for this research was received as Prime Minister Research Fellowship (PMRF) from Ministry of Education, Government of India by the first author.

Institutional Review Board Statement: Not applicable.

Informed Consent Statement: Not applicable.

Data Availability Statement: Data sharing is not applicable to this article.

Acknowledgments: The authors acknowledge the officials and staff of Patna Municipal Corporation (PMC) for their help and support. All the thanks and appreciation from our team to the editor and reviewers.

Conflicts of Interest: The authors declare no conflict of interest.

\section{References}

1. Taskin, A.; Demir, N. Life cycle environmental and energy impact assessment of sustainable urban municipal solid waste collection and transportation strategies. Sustain. Cities Soc. 2020,61,102339.

2. Kumar, S.; Smith, SR.; Fowler, G, et al. Challenges and opportunities associated with waste management in India. $R$ Soc Open Sci. 2017,4(3),160764.

3. Singh, S.; Solid waste management in urban India: imperatives for improvement. ORF Occas Pap. 2020,283,44.

4. Yadav, V.; Karmakar, S. Sustainable collection and transportation of municipal solid waste in urban centers. Sustain Cities Soc. 2020,53,101937.

5. Khandelwal, H.; Thalla, AK.; Kumar, S.; Kumar, R. Life cycle assessment of municipal solid waste management options for India. Bioresour Technol. 2019,288,121515.

6. Koushki, PA.; Al-Duaij, U.; Al-Ghimlas, W. Collection and transportation cost of household solid waste in Kuwait. Waste Manag. 2004,24(9),957-964.

7. Alam, R.; Chowdhury, MAI.; Hasan, GMJ.; Karanjit, B.; Shrestha, LR. Generation, storage, collection and transportation of municipal solid waste - A case study in the city of Kathmandu, capital of Nepal. Waste Manag. 2008,28(6),1088-1097.

8. Erses Yay, AS. Application of life cycle assessment (LCA) for municipal solid waste management: A case study of Sakarya. J Clean Prod. 2015,94,284-293.

9. Baidya, R.; Debnath, B.; De, D.; Ghosh, SK. Sustainability of modern scientific waste compacting stations in the city of Kolkata. Procedia Environ Sci. 2016,31,520-529.

10. Gilardino, A.; Rojas, J.; Mattos, H.; Larrea-Gallegos, G.; Vázquez-Rowe, I. Combining operational research and Life Cycle Assessment to optimize municipal solid waste collection in a district in Lima (Peru). J Clean Prod. 2017,156,589-603.

11. Rajcoomar, A.; Ramjeawon, T. Life cycle assessment of municipal solid waste management scenarios on the small island of Mauritius. Waste Manag Res. 2017,35(3),313-324.

12. Sharma, BK.; Chandel, MK. Life cycle assessment of potential municipal solid waste management strategies for Mumbai, India. Waste Manag Res. 2017,35(1),79-91.

13. Goulart, Coelho, LM.; Lange, LC. Applying life cycle assessment to support environmentally sustainable waste management strategies in Brazil. Resour Conserv Recycl. 2018,128,438-450.

14. Yadav, P.; Samadder, SR. A critical review of the life cycle assessment studies on solid waste management in Asian countries. J Clean Prod. 2018,185,492-515. 
15. Rana, R.; Ganguly, R.; Gupta, AK. Life-cycle assessment of municipal solid-waste management strategies in Tricity region of India. J Mater Cycles Waste Manag. 2019,21(3),606-623.

16. Khandelwal, H.; Thalla, AK.; Kumar, S.; Kumar, R. Life cycle assessment of municipal solid waste management options for India. Bioresour Technol. 2019,288,121515.

17. Pandey, MK. Solid Waste Management in Patna. 2014. Available online: https://www.nswai.com/docs/swm\%20patna\%201.pdf (accessed on 3 October 2021).

18. Bare, JC. Life cycle impact assessment research developments and needs. Clean Technol Environ Policy. 2010,12(4),341-351. 